\title{
Development of a preliminary essential medicines list for Canada
}

\author{
Michael S. Taglione BSc, Haroon Ahmad BA MA, Morgan Slater PhD MSc, Babak Aliarzadeh MPH MD, \\ Richard H. Glazier MD MPH, Andreas Laupacis MD MSc BA, Nav Persaud BA BSc MD MSc
}

See related research article by Steven Morgan and colleagues at www.cmaj.ca/lookup/doi/10.9778/cmaj.161082

\section{Abstract}

Background: Some evidence supports the use of a short list of essential medicines to improve prescribing. We aimed to create a preliminary essential medicines list for use in Canada.

Methods: The 2013 World Health Organization Model List of Essential Medicines was initially adapted by the research team. Fourteen Canadian clinicians gave suggestions for changes to the list. Literature relevant to each unique suggestion was gathered and presented to 3 clinician-scientists who used a modified nominal group technique to make recommendations on the suggested changes. Audits of prescriptions of 2 Toronto-based family health teams (an inner city clinic and a suburban site) between Aug. 1 , 2013, and July 30, 2014, were performed to identify common prescriptions that were not on the draft list. Literature relevant to these additional medications was gathered and shared with the clinician-scientist review panel to determine whether each should be added to the list, and a list was developed. The audits were repeated based on the final list to provide a preliminary assessment of the coverage of the list.

Results: The multistep process produced a list of 125 medications. The medications included on this list covered $90.8 \%$ and $92.6 \%$ of prescriptions at the inner city clinic and the suburban site, respectively. In total, $93 \%$ of the patients seen at the inner city clinic and $96 \%$ of the patients seen at the suburban clinic had all or all but 1 of their medications covered by the list.

Interpretation: A preliminary list of essential medicines was developed that covered most, but not all, prescriptions at 2 primary care sites. The list should be further refined based on wider input.

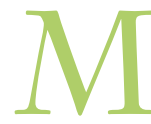
ore than 110 countries worldwide have developed essential medicines lists to fit their country's specific needs and context. ${ }^{1}$ The World Health Organization (WHO) has created a model list of essential medicines that is updated every 2 years based on efficacy, safety and tolerability. The WHO has stated that "each country has the direct responsibility of evaluating and adopting a list of essential drugs, according to its own policy in the field of health."2 In 2012, The House of Commons Standing Committee on Health recommended the establishment of a list as soon as possible. ${ }^{3}$ High-income countries that have implemented essential medicines lists have seen positive results, including improved quality of care, cost savings and more appropriate use of drugs. ${ }^{4}$

The large number of medications available in Canada poses a challenge for clinicians. ${ }^{5}$ Provincial formularies such as the Ontario Drug Benefit formulary, the Alberta Drug Benefit List and the Quebec Public Prescription Drug Insurance Plan list thousands of medications; more than 3800, 4000 and 7000 medications, respectively. ${ }^{6-8}$ A short list of essential medications might make it easier for clinicians to prescribe the most effective, safe and appropriate medications

Competing interests: None declared.

Disclaimer: Nav Persaud is an associate editor for CMAJ Open and was not involved in the editorial decision-making process for this article.

This article has been peer reviewed.

Correspondence to: Nav Persaud, nav.persaud@utoronto.ca

CMAJ Open 2017. DOI:10.9778/cmajo.20160122 
for their patients. ${ }^{9-11}$ In contrast to these large formularies, other countries have developed small lists that include only essential medicines. Sweden's "Wise List" of about 200 medications and the United Kingdom's regional short lists are successful examples of cost-effective, context-driven, evidencebased formularies in high-income countries. ${ }^{12,13}$

The adoption of an essential medicines list into public policy could lead to lower medication costs by concentrating price competition on a smaller number of drugs and could serve as a starting point for the development of a national drug coverage system. ${ }^{4}$ In Canada, about 1 in 10 people cannot afford prescribed medications, and more than 1 in 5 Canadians report that they or someone in their household has skipped doses, split pills or not filled their prescriptions to save money on medication in the previous 12 months. ${ }^{14,15}$ In addition, an essential medicines list could serve as a national formulary or assist in the development of one. The creation of a national formulary has been recommended in Canada for decades. ${ }^{16-19}$

The objective of this study was to create a preliminary essential medicines list for Canada based on the WHO essential medicines list through a multileveled, peer-reviewed process based on the most up-to-date clinical evidence, Canadian clinical practice guidelines and retrospective prescribing data.

\section{Methods}

\section{Adaptation of the WHO essential medicines list}

We (N.P., H.A.) adapted the 2013 WHO essential medicines list to create an initial essential medicines list for Canada. The purpose of this process was to identify the medicines on the WHO list that are applicable to Canada. ${ }^{20}$ Removals from the WHO list were made for 1 of 5 reasons: items were not medications, other medications on the list had better tolerated routes of administration (e.g., oral medication available instead of intravenous), the medications had the same indication as other listed medications, the medications were used for conditions that are uncommon in Canada or the medications were not medications prescribed by primary care providers. Any disagreements were resolved through discussion and consensus.

After reviewing the WHO list, we considered adding medications applicable to Canada that were not on the WHO list. We reviewed the following resources to determine if there were medicines applicable to Canada that were not on the WHO list: Canadian clinical practice guidelines, systematic reviews, health technology assessment reports and primary care formularies in Sweden ("Wise List") and the UK (National Health Service local formularies). This part of the process generated a first complete draft of the list for wider feedback.

\section{Peer reviewer feedback}

The adapted list of essential medicines was made publicly available on a website (cleanmeds.ca), and feedback on suggested changes to medications on the list was collected through the website. Each proposed change was classified as a replacement, an addition to or a removal from the list, and could be justified by at least 1 of the following criteria: evidence of efficacy, evidence of safety, route of administration and tolerability, dosing schedule, usefulness for other medical conditions and interactions with other medications. Respondents were allowed to make suggestions for any reason.

Multiple methods were used to recruit peer reviewers, which included primary care physicians, nurse practitioners, pharmacists and consultants or specialists practising in Canada. The first recruitment strategy involved the random selection of potential clinicians in Ontario. The College of Physicians and Surgeons of Ontario "Doctor Search" Tool and the Ontario College of Pharmacists "Member Search" Tool and a random sequence generator were used to select primary care physicians and pharmacists, respectively. The College of Nurses of Ontario "Find a Nurse" Tool was used to select registered nurses by entering 2 randomly selected letters in the last name search box and contacting nurses from that list using a random sequence generator. We contacted 100 peer reviewers through this method (50 physicians, 25 nurses and 25 pharmacists) and requested responses within 2 weeks.

The second recruitment strategy involved carefully selecting peer reviewers based on expertise, publications and academic involvement. We searched Canadian clinical practice guidelines using the repository maintained by the Canadian Medical Association and publications in the CMAJ and Canadian Family Physician in the previous 2 years for authors of papers in different therapeutic areas. We selected 60 peer reviewers in this fashion.

Both groups of reviewers (randomly and selected) were contacted by mail, fax or email with a description of the study and a website where they could submit their proposed list changes.

The third recruitment strategy involved direct advertising to clinicians at meetings, presentations, conferences and informal settings in Toronto and by email. In addition, an email was sent that invited clinicians to provide feedback through the St. Michael's Hospital Department of Family and Community Medicine mailing list ( 60 people) and the Innovations Strengthening Primary Healthcare through Research (INSPIRE-PHC) Network mailing list, which consists of more than 100 primary health care-oriented researchers and clinician-scientists.

\section{Clinician-scientist review of suggested changes}

Ten clinician-scientists, all primary care providers, were invited to join a panel to discuss the suggestions made by the peer reviewers. They were asked to participate based on their familiarity with clinical issues relevant to the medications on the list, their experience critically appraising clinical evidence (i.e., research training, experience), and a lack of relevant conflicts of interest (including those with pharmaceutical industry).

Based on the suggested additions, subtractions or substitutions to the adapted list made by the peer reviewers, we (N.P., M.T.) developed questions focused on efficacy and safety with support from an information scientist; a literature search was performed for each question. No searches were run for medicines that remained from the WHO list. Duplicate or similar suggestions were grouped together in a single question and subsequent literature search. Evidence was gathered from systematic reviews, meta-analyses, randomized control trials, the Compendium of 
Pharmaceuticals and Specialties, clinical practice guidelines and health technology assessment reports. The evidence for each recommendation was compiled into a document.

In the summer of 2015 , a series of meetings was held to review the results of the literature search. Each meeting included 3 of the clinician-scientists (voting members) and was facilitated by N.P. and M.T. (nonvoting members). The meetings employed a modified nominal group technique, involving independent consideration before the meeting, group discussion and voting on recommended changes to the adapted list. ${ }^{21}$ Each of the participating clinician-scientists was given the compiled document to review before the meeting and submitted comments on each suggestion to the research team. The research team compiled these comments and presented them during the meeting to facilitate discussion. Each clinician-scientist discussed their opinion without interruption, followed by open discussion. After each group discussion, the participating clinician-scientists voted by independently recommending whether or not the suggested change should be made based on the evidence gathered and from their own clinical expertise.

The strength of each recommendation (strong or weak) was determined by the 3 participating clinician-scientists. The final recommendations were deemed strong if all clinicianscientists were in agreement for or against the recommendation and at least 2 had made strong recommendations. If this criterion was not met, the recommendation was deemed weak in the direction of the most clinician-scientist votes. The strength of evidence supporting each recommendation was determined by vote, using the Grading of Recommendations Assessment, Development and Evaluation (GRADE) system. ${ }^{22}$ The strength of the recommendation reflects the importance of the decision, whereas the strength of the evidence reflects how unlikely it is that new evidence would change the recommendation.

\section{Identification and addition of commonly prescribed medications}

To identify commonly prescribed medications missing from the list, we audited all prescriptions written in 2 primary care sites: an inner city site, located in downtown Toronto, which serves a diverse inner city population (Health Centre at 80 Bond, St. Michael's Hospital Academic Family Health Team) and a suburban site, the North York Family Health Team, which is one of the largest family health teams in Ontario. All prescriptions made between Aug. 1, 2013, and July 30, 2014, were included in the audit. Data for all patients seen at the St. Michael's site were extracted from its electronic medical record. Data were obtained from the University of Toronto PracticeBased Research Network (UTOPIAN) for 65 family physicians who were members of the North York Family Health Team.

For each prescription, we (M.T., N.P.) determined whether the prescribed medication was included on the list or, if the prescribed medication was not on the list, whether there was an equivalent medication on the list. Medications were considered equivalent if they treated the same condition (e.g., atomoxetine and methylphenidate for attention deficit-hyper- activity disorder) or were from the same class of medications (e.g., angiotensin-converting enzyme inhibitors). Repeat prescriptions of the same medication prescribed to the same patient were removed.

A medication was considered to have coverage if it or an equivalent was on the draft essential medicines list. A literature search was conducted for any commonly prescribed medications that were identified as not having coverage and not previously reviewed to determine their efficacy, safety and tolerability. Three of the clinician-scientists repeated the previously described method and made recommendations as to whether these medications should be added, resulting in the development of the preliminary list of essential medications for Canada.

\section{Audit of the list using prescribing data}

Upon completion of the list, the audit of the 2 Toronto clinics was updated to provide a preliminary analysis of the list's medication coverage overall and at the individual patient level. We determined the fraction of individual patients who had all, all but 1 , and all but 2 or more medications covered by reviewing a list of the unique medications prescribed to each patient over the 12-month study period using the same definition of equivalence as above.

\section{Patient and community involvement}

A panel of 11 community members was recruited from the area surrounding St. Michael's Hospital by canvassing, by random digit dialing and through existing community groups. The community guidance panel met monthly during the development of the list and provided input on issues including the criteria used to select medications, how to maintain the list and the knowledge-translation strategy. The community guidance panel members did not suggest particular changes to the medications on the list.

\section{Ethics approval}

The study was approved by the Research Ethics Board of St. Michael's Hospital.

\section{Results}

\section{Adaptation of the WHO essential medicines list}

The WHO list contained 448 items. In creation of our initial list, 368 items were removed. Removals included 59 items that were not medications (e.g., condoms), 37 had other medications on the list with better-tolerated routes of administration, 136 medications had the same indication as other listed medications (e.g., metoclopramide is listed, but ondansetron is not), 52 medications were used for uncommon indications in Canadian primary care (e.g., the antiparasitic ivermectin), and 84 were medications used by specialists (e.g., the chemotherapeutic agent vincristine). Twenty-eight medications were added to the list based on Canadian clinical practice guidelines, systematic reviews, health technology assessment reports and international primary care formularies (e.g., the bisphosphonate alendronate). This adapted list contained 108 medications (Figure 1). 


\section{Peer reviewer suggestions}

Eight of the 60 (13\%) clinicians from the carefully selected group submitted feedback, and 6 of the clinicians from the direct-advertising group submitted feedback. None of the 100 clinicians randomly selected from the College databases of physicians, pharmacists or nurses responded. The 14 clinicians who submitted feedback included 5 primary care physicians, 5 pharmacists, 2 nurse practitioners and 2 specialists. Seven of the clinicians were from Ontario and 7 were from other Canadian provinces.

A total of 46 unique suggestions were obtained from the peer reviewers. Among the suggestions given were 16 replacements of medications on the list, 20 additions to the list and 10 removals from the list.

\section{Clinician-scientist review}

Five clinician-scientists were recruited and 3 attended each review meeting. The clinician-scientists reviewed each of the 46 suggestions and made recommendations on each. They agreed with 11 of the 16 replacement suggestions, 12 of the 20 suggestions to add medications, and 6 of the 10 removal suggestions. Overall, they gave 13 strong recommendations and 16 weak recommendations for the changes, as well as 6 strong recommendations and 11 weak recommendations against the changes. About three-quarters of the GRADE levels (76\%) agreed upon by the clinician-scientists indicated high- or moderate-level evidence for the recommended changes.

A summary of the peer review suggestions, the panel's decisions and the changes made to the list are in Appendix 1 (available at www.cmajopen.ca/content/5/1/E137/suppl/ DC1), and the literature package distributed to the clinicianscientists can be found at cleanmeds.ca.

\section{Identification and addition of commonly prescribed medications}

Prescribing audits of the 2 primary care sites were completed to identify frequently prescribed medications without list coverage. Literature was gathered for 16 additional medications identified and later discussed by the clinician-scientist panel. The panel gave 4 strong recommendations and 7 weak recommendations for a total of 11 additions and 5 weak recommendations against changes. Of the GRADE levels agreed upon by the panel, there was high- or moderate-level evidence for $81 \%$ of the recommendations. A summary of the clinician-scientist decisions are in the Appendix 2 (available at www.cmajopen.ca/content/5/1/E137/suppl/DC1); the final list of 125 essential medicines is shown in Table 1 . The 25 most prescribed medications at each site without coverage on the list are shown in Appendix 3 (available at www.cmajopen. $\mathrm{ca} /$ content/5/1/E137/suppl/DC1).

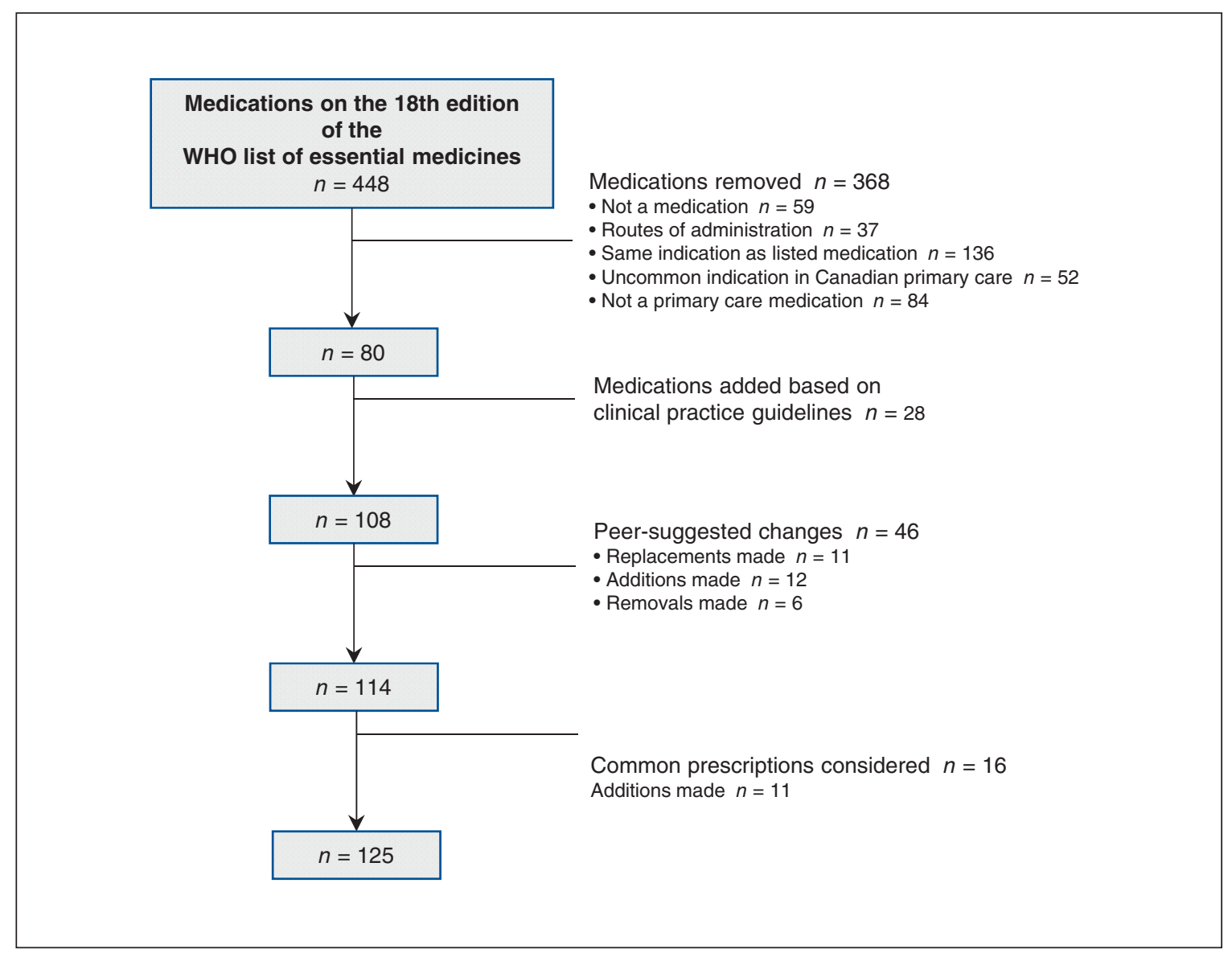

Figure 1: Additions, removals and replacements to the list of essential medications throughout development. 


\section{Audit of the list using prescribing data}

There were 19074 medications prescribed to 4777 patients at the inner city site during the period assessed. The mean age of this patient group was 44 years; $56.8 \%$ were female (Table 2).
The inner city site had $90.8 \%$ total prescription coverage with the preliminary list of essential medications. Of the patients at the inner city site, $72.3 \%$ had all their medications covered on the list, $20.8 \%$ had all but 1 medication covered, and $6.9 \%$

\begin{tabular}{|c|c|c|c|}
\hline $\begin{array}{l}\text { World Health Organization (WHO) } \\
\text { class }^{1}\end{array}$ & & Medicines & \\
\hline $\begin{array}{l}\text { Antiallergics and medicines used } \\
\text { in anaphylaxis }\end{array}$ & Cetirizine* $^{*}$ & Diphenhydramine* & Epinephrine† \\
\hline Anticonvulsive medication & $\begin{array}{l}\text { Carbamazepine, } \\
\text { gabapentin* }\end{array}$ & Phenytoin & Valproic acid $†$ \\
\hline Anti-infective medicines & $\begin{array}{l}\text { Abacavir*, amoxicillin, } \\
\text { amoxicillin/clavulanic } \\
\text { acid, azithromycin, } \\
\text { cephalexin, ciprofloxacin, } \\
\text { clindamycin, clotrimazole }\end{array}$ & $\begin{array}{l}\text { Cloxacillin, dolutegravir*, } \\
\text { doxycycline, efavirenz, } \\
\text { emtricitabine, } \\
\text { fluconazole, gentamicint, } \\
\text { lamivudine }\end{array}$ & $\begin{array}{l}\text { Levofloxacin, metronidazole, } \\
\text { nitrofurantoin, nystatin, } \\
\text { sulfamethoxazole/ } \\
\text { trimethoprim, tenofovir, } \\
\text { trimethoprim, valacyclovir* }\end{array}$ \\
\hline Antimigraine medicines & Eletriptan* & & \\
\hline $\begin{array}{l}\text { Antineoplastic and } \\
\text { immunosuppressives }\end{array}$ & Methylprednisolone & Prednisone* $^{*}$ & Tretinoin \\
\hline Antiparkinsonism medicines & Benztropine* & Levodopa/carbidopa & \\
\hline Cardiovascular medicines & $\begin{array}{l}\text { Amlodipine, } \\
\text { atorvastatin }{ }^{*} \text {, bisoprolol, } \\
\text { candesartan* }\end{array}$ & $\begin{array}{l}\text { Clopidogrel, diltiazem, } \\
\text { labetalol* }\end{array}$ & $\begin{array}{l}\text { Pravastatin*, ramipril*, } \\
\text { nitroglycerin* }\end{array}$ \\
\hline Dermatological (topical) & $\begin{array}{l}\text { Benzoyl peroxide, } \\
\text { betamethasone, fusidic } \\
\text { acid }^{*}\end{array}$ & $\begin{array}{l}\text { Hydrocortisone†, } \\
\text { mupirocin, permethrin }\end{array}$ & Salicylic acid, urea \\
\hline Diuretics & Chlorthalidone $^{*}$ & Furosemide $†$ & Spironolactone $†$ \\
\hline Eye preparations & Latanoprost & Olopatadine* & Pilocarpine \\
\hline Gastrointestinal medicines & $\begin{array}{l}\text { Metoclopramide } \dagger \text {, } \\
\text { pantoprazole }\end{array}$ & $\begin{array}{l}\text { Polyethylene glycol } \\
3350^{\star}, \text { ranitidine }\end{array}$ & Senna†, sulfasalazine† \\
\hline $\begin{array}{l}\text { Hormones, other endocrine } \\
\text { medicines, and contraceptives }\end{array}$ & $\begin{array}{l}\text { Alendronate }{ }^{\star} \text {, conjugated } \\
\text { estrogens }{ }^{*} \text {, copper- } \\
\text { containing IUD, } \\
\text { estradiol*, ethinyl } \\
\text { estradiol/levonorgestrel, } \\
\text { Gliclazide }\end{array}$ & $\begin{array}{l}\text { Insulin - long acting, } \\
\text { Insulin - short acting, } \\
\text { Levonorgestrel-releasing } \\
\text { implant, Levothyroxine, } \\
\text { medroxyprogesterone, } \\
\text { metformin }\end{array}$ & $\begin{array}{l}\text { Methimazole*, potassium, } \\
\text { propylthiouracil, } \\
\text { testosterone, vaginal ring } \\
\text { eluting etonogestrel and } \\
\text { ethinyl estradiol }\end{array}$ \\
\hline $\begin{array}{l}\text { Medicines acting on the } \\
\text { respiratory tract }\end{array}$ & $\begin{array}{l}\text { Beclomethasone, } \\
\text { budesonide } \dagger \\
\text { fluticasone }^{*}\end{array}$ & Ipratropium, salbutamol & Salmeterol ${ }^{*}$, tiotropium* \\
\hline Medicines affecting the blood & $\begin{array}{l}\text { Ferrous fumarate, folic } \\
\text { acid }\end{array}$ & Rivaroxaban* & Warfarin \\
\hline Medicines for diseases of joints & Allopurinol† & Methotrexate $†$ & \\
\hline $\begin{array}{l}\text { Medicines for mental and } \\
\text { behavioural disorders }\end{array}$ & $\begin{array}{l}\text { Atomoxetine*, clozapine, } \\
\text { diazepam†, fluoxetinet, } \\
\text { haloperidol† }\end{array}$ & $\begin{array}{l}\text { Lithium, methadone, } \\
\text { naltrexone*, nicotine } \\
\text { replacement therapy }\end{array}$ & $\begin{array}{l}\text { Nortriptyline }{ }^{*}, \text { risperidone, } \\
\text { sertraline }^{*}, \text { varenicline }^{*}\end{array}$ \\
\hline $\begin{array}{l}\text { Medicines for pain and palliative } \\
\text { care }\end{array}$ & $\begin{array}{l}\text { Acetaminophen, ASA†, } \\
\text { baclofen* }^{*}\end{array}$ & $\begin{array}{l}\text { Dexamethasonet, } \\
\text { hydromorphone, } \\
\text { lbuprofen† }\end{array}$ & $\begin{array}{l}\text { Loperamide, morphine†, } \\
\text { naproxen* }\end{array}$ \\
\hline Vitamins and minerals & Vitamin B12* & Vitamin D & \\
\hline $\begin{array}{l}\text { Medicines that do not fall under a } \\
\text { WHO class }\end{array}$ & Finasteride*, oxybutynin* & Sildenafil $^{*}$ & Tamsulosin* \\
\hline \multicolumn{4}{|c|}{ 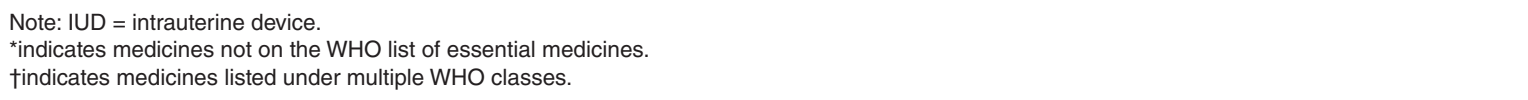 } \\
\hline
\end{tabular}


had 2 or more medications not covered, with $73.3 \%$ of those receiving 6 or more prescriptions over the year (Table 3; Appendix 4, available at www.cmajopen.ca/content/5/1/E137/ suppl/DC1).

There were 119862 medications prescribed to 35544 patients at the suburban site. The mean age of this patient group was 50 years; $67.2 \%$ were female. There was a greater proportion of women at the suburban site because of a large obstetrical practice.

The suburban site had $92.6 \%$ total prescription coverage with the preliminary list of essential medications. Of the patients at the suburban site, $79.8 \%$ had all of their medications covered on the list, $16.4 \%$ had all but 1 medication covered, and $3.7 \%$ had 2 or more medications not covered, with $74.3 \%$ of those receiving 6 or more prescriptions over the year (Table 3; Appendix 5, available at www.cmajopen.ca/ content/5/1/E137/suppl/DC1).

Table 2: Patient characteristics at the audit sites

\begin{tabular}{|lcc|}
\hline & Inner city site & Suburban site \\
\hline No. of patients & 4777 & 35544 \\
\hline $\begin{array}{l}\text { Sex, no. (\%) } \\
\text { Male: } 2063(43) \\
\text { Female: } 2714(57)\end{array}$ & $\begin{array}{c}\text { Male: } 11643(33) \\
\text { Female: } 23900(67) \\
\text { Not specified: } 1\end{array}$ \\
\hline $\begin{array}{l}\text { Age, yr, } \\
\text { mean } \pm \text { SD }\end{array}$ & $44 \pm 20$ & $50 \pm 22$ \\
\hline Note: SD $=$ standard deviation. & \\
\hline
\end{tabular}

Table 3: Medication coverage at the audit sites

\begin{tabular}{|lcc|}
\hline & Inner city site & Suburban site \\
\hline $\begin{array}{l}\text { No. of medications } \\
\text { prescribed }\end{array}$ & 19074 & 119862 \\
\hline $\begin{array}{l}\text { No. }(\%) \text { of medications } \\
\text { included on the list (\%) }\end{array}$ & $10238(53.7)$ & $59108(49.3)$ \\
\hline $\begin{array}{l}\text { No. of medications with } \\
\text { equivalents on the list }\end{array}$ & $7077(37.1)$ & $51873(43.3)$ \\
\hline $\begin{array}{l}\text { No. of medications without } \\
\text { list coverage }\end{array}$ & $1759(9.2)$ & $8881(7.4)$ \\
\hline
\end{tabular}

\section{Interpretation}

We adapted the WHO's Model List of Essential Medicines using a 4-step process involving a small group of Canadian clinicians and clinician-scientists.

The preliminary essential medicines list for Canada that we developed contains only 125 medications, about half of the number of medications on the Swedish Wise List and about a quarter of the medications on the WHO list. The small size of the list might allow clinicians to learn more information about fewer drugs and could improve appropriateness of clinician prescribing. ${ }^{13,23}$
The list had more than $90 \%$ medication coverage in the audit we conducted at each of the clinics; more than $90 \%$ of patients had all or all but 1 of their medications covered by the list. These preliminary results suggest that, although smaller than the essential medicines lists of other countries, this list still covers most medications and patients.

With a more comprehensive assessment of the preliminary list's national coverage, the list could be used as the national list of essential medications alluded to in the Federal Minister of Health's mandate letter. ${ }^{24}$

\section{Limitations}

The first draft of the list was based on an informal process; however, we used the peer review process to address any inappropriate additions, and the peer review process and prescribing audit to address any inappropriate omissions. We considered equivalent medications that others might view as different (e.g., atomoxetine and methylphenidate).

Only 14 peer reviewers of the hundreds of clinicians contacted provided feedback; the final list we developed may have been different if a larger number of clinicians had provided input. However, even with this number of peer reviewers, we received 46 unique list suggestions and reviewed an additional 16 medications based on prescribing data.

We had a small panel of 3 clinician-scientists making the final recommendations for the list, and this could have limited the variety of opinions during discussion. However, the small number of clinician-scientists allowed for decisions to be made efficiently.

We only compared the essentials list with prescribing patterns in 2 primary care sites from the Toronto area, which may not be representative of provincial and national prescribing. Efforts to analyze national and provincial data are in progress. ${ }^{25}$

This preliminary list excludes cancer treatments and other medicines prescribed outside of primary care. It will only be useful if it is accepted and implemented by the public, clinicians and decision-makers. Further work is needed to determine how acceptable an essential medications list is to stakeholders in Canada.

\section{Conclusion}

We have developed a preliminary short list of essential medications that covers most, but not all, current prescribed medications in primary care. The list can be refined in the future based on wider input, and it should be continuously revised based on new evidence. Future work should determine the applicability of the list across Canada, the impact of list adoption on actual prescribing and the effects of listdriven prescribing on patients.

\section{References}

1. Essential medicines selection - National medicines list/formulary/standard treatment guidelines. Geneva: World Health Organization; 2014. Available: www.who.int/selection_medicines/country_lists/en/ (accessed 2017 Jan. 31).

2. The selection of essential drugs: report of the WHO expert committee. World Health Organ Tech Rep Ser 1977:1-36.

3. Smith J. Drug supply in Canada: a multi-stakeholder responsibility. Report of the Standing Committee on Health. Ottawa: Parliament of Canada, June 2012. 
Available: www.parl.gc.ca/content/hoc/Committee/411/HESA/Reports/ RP5640047/hesarp09/hesarp09-e.pdf (accessed 2017 Jan. 31).

4. Eom G, Grootendorst P, Duffin J. The case for an essential medicines list for Canada. CMA7 2016;188:E499-503.

5. Sketris IS, Lummis H, Langille E. Optimal prescribing and medication use in Canada: challenges and opportunities. Toronto: Health Council of Canada; 2007.

6. Ontario public drug programs: drugs funded by Ontario Drug Benefit (ODB) program [formulary]. Toronto: Ontario Ministry of Health and Long-Term Care; 2014. Available: www.health.gov.on.ca/en/pro/programs/drugs/odbf_ mn.aspx (accessed 2015 July 17).

7. Alberta Drug Benefit List (ABDL). Edmonton: Alberta Health; 2015. Available: www.health.alberta.ca/services/drug-benefit-list.html (accessed 2015 July 17).

8. Prescription drug insurance - Prescription drugs covered: Prescription drugs covered by the Public Prescription Drug Insurance Plan; Québec: Régie de l'assurance maladie du Québec; 2015. Available: www.ramq.gouv.qc.ca/en/ citizens/prescription-drug-insurance/pages/prescription-drugs-covered.aspx (accessed 2015 Juy 17).

9. Yakabowich MR, Keeley G, Montgomery PR. Impact of a formulary on personal care homes in Manitoba. CMA7 1994;150:1601-7.

10. Feely J, Chan R, Cocoman L, et al. Hospital formularies: need for continuous intervention. BM7 1990;300:28-30.

11. King MA, Roberts MS. The influence of the Pharmaceutical Benefits Scheme (PBS) on inappropriate prescribing in Australian nursing homes. Pharm World Sci 2007;29:39-42.

12. Gustafsson LL, Wettermark B, Godman B, et al.; Regional Drug Expert Consortium. The 'wise list' - a comprehensive concept to select, communicate and achieve adherence to recommendations of essential drugs in ambulatory care in Stockholm. Basic Clin Pharmacol Toxicol 2011:108:224-33.

13. Hill-Smith I. Sharing resources to create a district drug formulary: a countywide controlled trial. Br 7 Gen Pract 1996;46:271-5.

14. Law MR, Cheng L, Dhalla IA, et al. The effect of cost on adherence to prescription medications in Canada. CMA7 2012;184:297-302.

15. Prescription drug access and affordability an issue for nearly a quarter of all Canadian households. Vancouver: Angus Reid Institute; 2015. Available: http://angusreid.org/wp-content/uploads/2015/07/2015.07.09-Pharma.pdf (accessed 2017 Jan. 31).

16. Morgan S, Daw J, Law MR. Rethinking pharmacare in Canada [commentary]. Toronto: C.D. Howe Institute; 2013:384.

17. Romanow RJ. Building on values: the future of health care in Canada - Final report. Ottawa: Public Works and Government Services Canada; 2002. Available: http://url dsp-psd.pwgsc.gc.ca/Collection/CP32-85-2002E.pdf (accessed 2017 Jan. 31).

18. Gagnon MA. A roadmap to a rational pharmacare policy in Canada. Ottawa: Canadian Federation of Nurses Unions; 2014.

19. Kirby MJL, LeBreton M. The health of Canadians - The federal role. Final report, Volume 6: recommendations for reform. Ottawa: Parliament of Can- ada; 2002. Available: www.parl.gc.ca/content/sen/committee/372/soci/rep/ repoct02vol6-e.htm (accessed 2017 Jan. 31)

20. WHO Model List of Essential Medicines. Geneva: World Health Organization; 2013. Available: www.who.int/medicines/publications/essentialmedicines/18th EML_Final_web_8Jul13.pdf (accessed 2017 Jan. 31).

21. Nair R, Aggarwal R, Khanna D. Methods of formal consensus in classification/ diagnostic criteria and guideline development. Semin Artbritis Rheum 2011; 41:95-105.

22. Guyatt GH, Oxman AD, Vist GE, et al.; GRADE Working Group. GRADE: an emerging consensus on rating quality of evidence and strength of recommendations. BM7 2008:336:924-6.

23. Avery AJ, Walker B, Heron T, et al. Do prescribing formularies help GPs prescribe from a narrower range of drugs? A controlled trial of the introduction of prescribing formularies for NSAIDs. Br 7 Gen Pract 1997;47:810-4.

24. Minister of health mandate letter. Ottawa: Office of the Prime Minister of Canada; 2015. Available: http://pm.gc.ca/eng/minister-health-mandate-letter (accessed 2017 Jan. 31).

25. Morgan SG, Li W, Yau B, et al. Estimated effects of adding universal public coverage of an essential medicines list to the existing complement of public drug plans. CMAF 2017;189:E295-302.

Affiliations: Faculty of Medicine (Taglione), University of Toronto; Li Ka Shing Knowledge Institute (Taglione, Ahmad, Glazier, Laupacis, Persaud); Department of Family and Community Medicine (Slater, Glazier, Persaud), St. Michael's Hospital; Department of Family and Community Medicine (Aliarzadeh, Glazier, Laupacis, Persaud), University of Toronto; University of Toronto Practice Based Research Network (Aliarzadeh); Institute for Clinical Evaluative Sciences (Glazier), Toronto, Ont.

Contributors: Nav Persaud conceived of the study with input from Andreas Laupacis and Richard Glazier; Michael Taglione, Haroon Ahmad, Morgan Slater, Babak Aliarzadeh and Nav Persaud conducted the study; Andreas Laupacis, Richard Glazier and Nav Persaud interpreted the findings. Michael Taglione, Haroon Ahmad and Nav Persaud wrote the first manuscript draft; all authors were involved in revising it critically for important intellectual content and all approved of the final version. All authors will be accountable for all aspects of the work in ensuring that questions related to the accuracy or integrity of any part of the work are appropriately investigated and resolved.

Supplemental information: For reviewer comments and the original submission of this manuscript, please see www.cmajopen.ca/content/5/1/ E137/suppl/DC1 